\title{
Evolution of Lymphoid Tissue in the Vermiform Appendix in human Fetuses
}

\author{
Ch. N. V. Bharath ${ }^{1}$, Dr.Swayam jothi.S, ${ }^{2}$ Dr.Janaki.M ${ }^{3}$ \\ ${ }^{1}$ Department of Anatomy, Santhiram Medical College, NH-18, Nandyal-518501, Kurnool Dt., A.P, India. \\ ${ }^{2}$ Department of Anatomy, Satyasai Medical College and research institute, Kancheepuram, Chennai, India. \\ ${ }^{3}$ Department of Pathology, Santhiram Medical College, NH-18, Nandyal-518501, Kurnool Dt., A.P, India.
}

\begin{abstract}
In humans, Vermiform appendix is a small, finger-sized structure, found at the end of caecum and located near the beginning of large intestine. The lymphoid tissue starts appearing in the wall of the appendix around the $17^{\text {th }}$ week of intra uterine life. The abdomen localization according to regions (quadrants) and classification of vermiform appendix position are retrocecal, retroileal, pelvic, free. The retroileal position of the vermiform appendix was most observed among retrocecal, pelvic, and free positions. The vermiform appendix is considered as the organ with highest topographic variation in the abdomen. The structural modifications that emerge and develop along years determine the appearance of appendix found in adult individuals with narrow base at $2.5 \mathrm{~cm}$ from the ileocecal junction. The high frequency of the retroileal position within the first year of life corroborates the low incidence of vermiform appendix inflammation rate among young children. The retroileal position associated to the gravity effect represents strong indication of protection against mechanical obstructions of lumen.
\end{abstract}

Key words: Lymphoid tissue, retro ileal, retro cecal, pelvic, free.

\section{Introduction}

During the fifth fetal week the appendix develops as a bud at the junction of the small and large bowel and undergoes rapid growth in to a pouch. During fetal and early life, the lumen is wider at the base, like a funnel. The epithelial and the reticular tissue structure in the area of cupola including the lymphoid follicle have been studied and B-Lymphocytes have been stated to be present in the appendix of a $17^{\text {th }}$ week-old fetus. As the fetus is further developing, the number of lymphocytes in the appendix increases. The amount of $\mathrm{T}$ Lymphocytes is practically constant, and that of B-lymphocytes increases. Although it was thought the appendix itself could be the site for B-lymphocyte induction (a Bursa of Fabricius equivalent). The lymphoid formations of appendix are necessary for certain local protective reactions and already in the fetus they begin to participate in the general system of the organisms immunogenesis. The lymphoid tissue is known for certain to be involved in antibody production. These antibodies are two types 1.IgA type immunoglobulins for secretary or mucosal surface immunity 2.IgM type immunoglobulins for humoral or blood stream immunity.

\section{Materials and Methods}

This descriptive research was submitted to the Intuitional Ethical Committee of the Santhiram Medical College, Nandyal.

Ten dead fetuses of different age groups were collected from OBG Department of Santhiram Medical College after consent from the parents these will be utilized for the present study.

Study will be carried out in the Department of Anatomy, Santhiram Medical College, Nandyal.

Inclusion criteria: - Fetuses collected due to miscarriages (hormonal defect, genetic defect, abruptio placenta, placenta previa).

Exclusion criteria: - Fetus with anomalies of GIT tract.

Foetuses will be grouped into three groups by depending on the age.

1) Group A -3 pieces from I st trimester (Fig: 1)

2) Group B - 2 pieces from II nd trimester (Fig: 2)

3) Group $\mathrm{C}-5$ pieces from III rd trimester (Fig: 3 )

The ileocecal region was checked before dissection (Fig: 4) for the verification of the abdomen localization according to regions (quadrants) and classification of vermiform appendix position (retrocecal, retroileal, pelvic, free).Following distal portion of ileum,caecum and proximal portion of the large intestine were dissected removed and fixed with $10 \%$ formaldehyde. The length of the vermiform appendix was initially measured. (Fig: 5) 


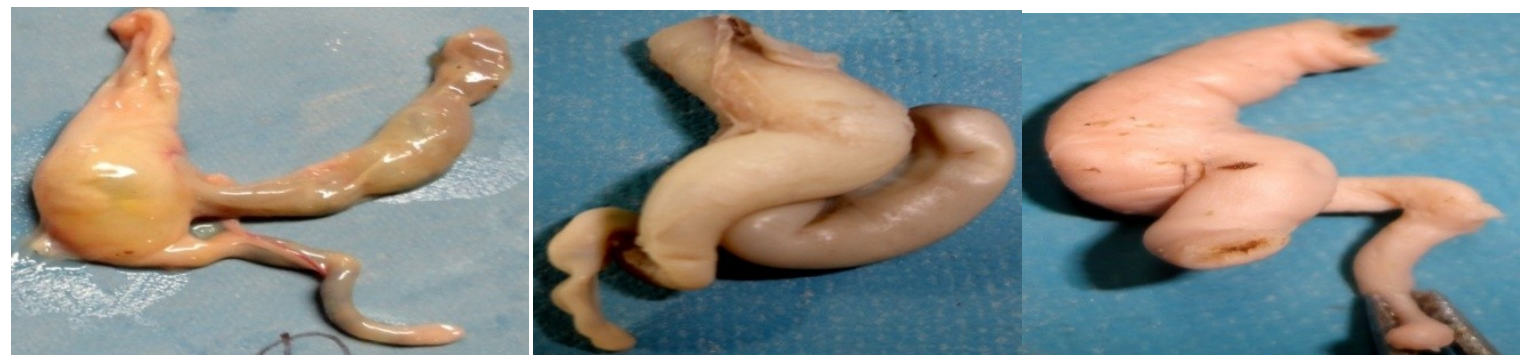

Fig: 1 Ileocecal region of fetus with in 3rd trimester

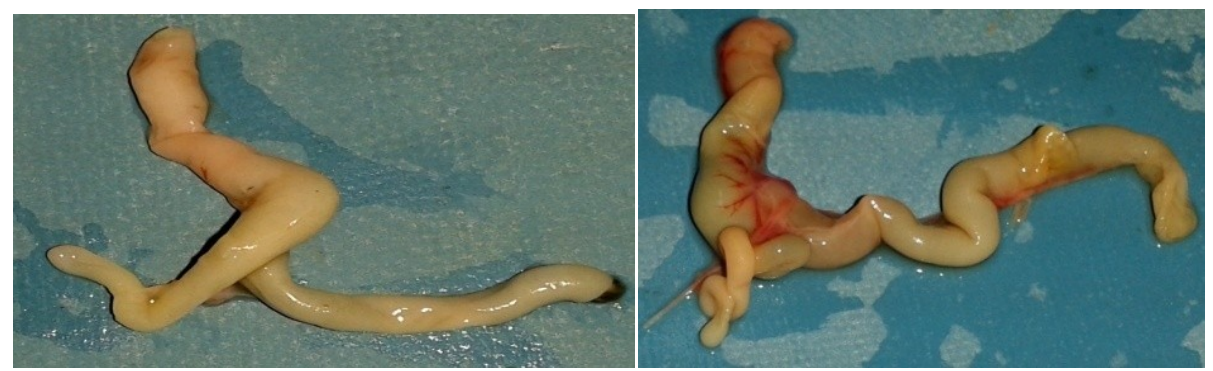

Fig: 2 Ileocecal region of fetus with in 6th trimester.

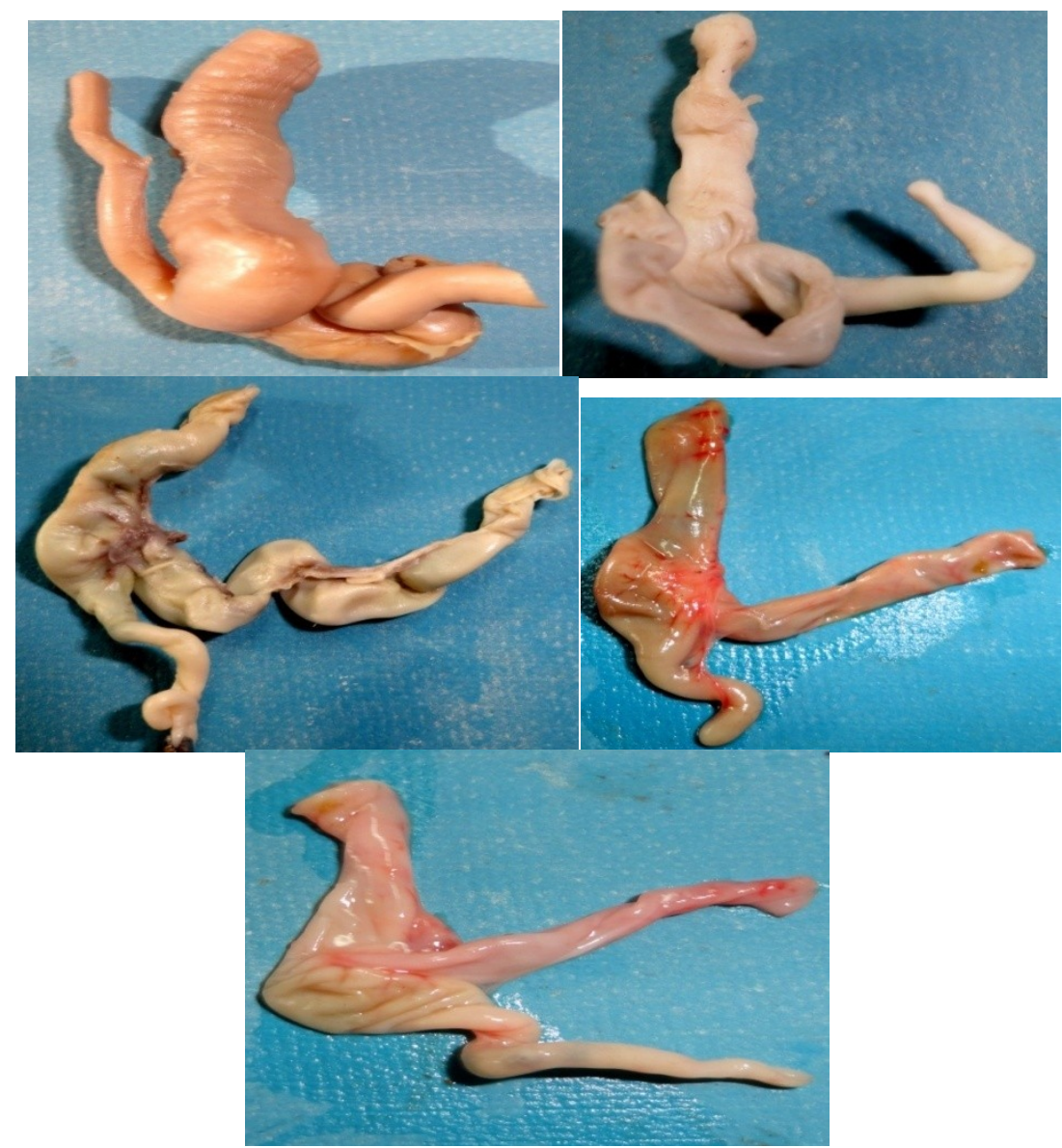

Fig: 3 Ileocecal region of fetus with in 9th trimester. 


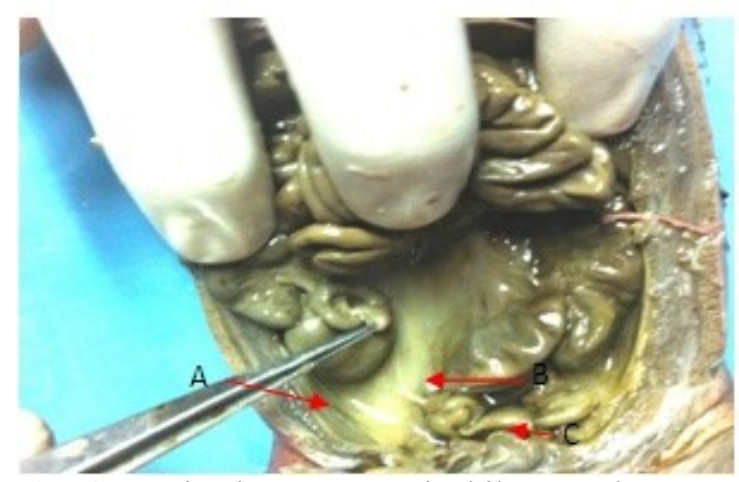

Fig: 4 Junction between terminal ileum and caecum A.Caecum, B.Ileum, C.Vermiform appendix.

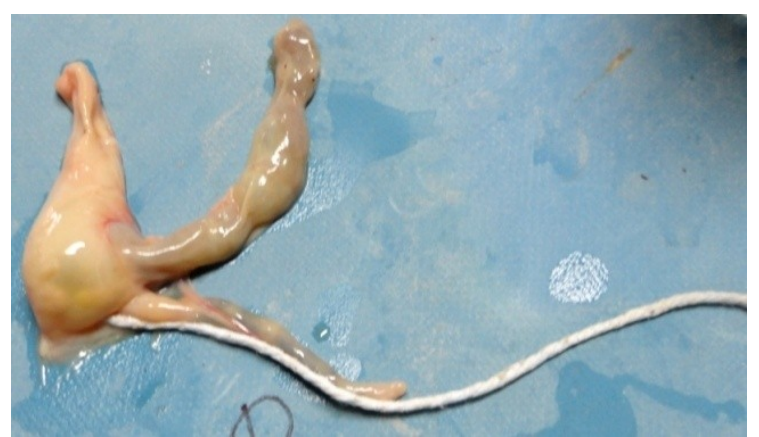

Fig: 5 showing measure the length $(\mathrm{cm})$ of vermiform appendix by using thread.

\section{Results}

The vermiform appendix development biology among 3 trimesters of age were studied. Among the ten (10) transition pieces studied (4 male and 6 female).

The caecum fixation site in the peritoneal cavity was more frequent at right iliac fossa region and the retroileal position of the vermiform appendix was most observed among retrocecal, pelvic, and free positions. (Table: 1$)$.

Table: 1 Showing Vermiform appendix position in relation to abdomen regions

\begin{tabular}{|c|c|c|}
\hline Vermiform appendix & \multicolumn{2}{|c|}{ Caecum } \\
\hline Pelvic & Right iliac fossa & Right hypo chondria \\
\hline Retrocecal & 3 & \\
\hline Retroileal & 3 & 1 \\
\hline Free & 4 & 0 \\
\hline
\end{tabular}

The length $(\mathrm{cm})$ of vermiform appendix ranged from $1.5-4$ with average of $2.5 \mathrm{~cm}$ (Fig: 5)

\section{Discussion}

The vermiform appendix was considered as a rudimentary and vestigial organ, which effective contribution along with other organs from the digestive system has been questioned (Cancado 1988).

The analysis of results of this study has demonstrated that its average length is similar to that presented by Brady and Katzarski (1979) and Ajmani, ML\&Ajmani.K (1983).Collins (1932) reports that the largest appendix described in literature found in 1980 by Grauer measured $33 \mathrm{~cm}$ in adult cadaver.

The vermiform appendix is considered as the organ with highest topographic variation in the abdomen. These studies have reported a variation of results in relation to other abdominal \& pelvic organs(Ajmani ML and AjmaniKin1983,Berry(1895), Collins(1932),Ferguson(1891),FitzGerald,NolanandO'Neill(1971), Garis(1941),M alas, Gokamen and Sulak $(2001,2004)$.In this work the position of vermiform appendix was predominantly retro iliac position. Berry (1895), Collins (1932), FitzGerald, Nolan and O’Neill (1971). 
Literature considers that the cecal -appendicular transition according to the external appearance, presence of 3 distinct shapes. Between birth and $1^{\text {st }}$ year of life, the cecum presents pyramidal shape, where the appendix prolongs from its apex. In young child, the cecum presents a differentiated growth and approximates the implantation of the appendix of the terminal ileum. These structural modifications that emerge and develop along years determine the appearance of appendix found in adult individuals with narrow base at $2.5 \mathrm{~cm}$ from the ileocecal junction (Garis, 1941).

Many authors agree that the lower edge of the cecum at the right side of the vermiform appendix opening expands and grows more in length that in the left lower edge and besides dislocating the base of the vermiform appendix towards the ileum, grants an anatomic shape to the cecal appendicular region similar to that foundinadultindividuals.(Condon,1986;Didio,HabrGama,Gamaetal,1999;Garis,1941,Mcray,1984;Testut\&Latarj et,1952).

It is observed that anatomic pieces still with no Cul-de-sac appearance, presented lower expansion of vermiform appendix predominantly retroileal position, as also described in publications (Smith, 1911, Ojeifo, Ejiwunmi, Iklaki, 1989).

\section{Conclusion}

The high frequency of the retroileal position within the first year of life corroborates the low incidence of vermiform appendix inflammation rate among young children. The retroileal position associated to the gravity effect represents strong indication of protection against mechanical obstructions of lumen.

The average length of the vermiform appendix was $2.5 \mathrm{~cm}$ with maximum extension of $4 \mathrm{~cm}$, reason why it cannot be considered as a rudimentary organ under invoulution. The vermiform appendix base presents a relative decrease in size after birth. Its spatial shape at the age of two years is very close to that found in adult individuals. The emergence and growth of the distance from the left edge of the vermiform appendix implantation to the ileum is the most important anatomic parameter in the acquition of the ultimate shape of organ, which is similar to that found in adult individuals. The emergence of the left edge establishes the limit on the anatomic definition of the transition between cecum \&vermiform appendix.

\section{References}

[1]. Ajmani, Ml.and AJmani, K. The position, length, and arterial supply of Vermiform appendix.Anatomisher aneiger.1983, vol.153, no.4, p.369-374.

[2]. Berry, Mj.Appendicectomy in child hood: analysis of 105 negative Explorations. American journal of surgery.1982, vol144, no.3, p.335-337.

[3]. Cangado, Jrapendicite aguda coutra afeccous doappendice in dani R Castro, LP(Ed) Gastroenterological 2 Ed Rio de janerio gurnabara koogan S.A, 1988 p 822-829(vol 2).

[4]. Condon, Re, Appendicities in sabiston, Dc(Ed) Textbook of surgery 13 ed TokyoWB Saunders company 1986 p 967-981.

[5]. COLLINS, DC. The length and position of the vermiform appendix. American journal of surgery, 1932, Vol 96, p-10448.Pmid:17866891.

[6]. Ferguson, J.Some important points regarding the appendix Vermiformis.American journal of medicine sciences $1891 \mathrm{p} 61-62$.

[7]. Fitzerald, Mit. Nolan, Jp and O’Neill, Mn the position of the human caecum in Fetal life. Journal of anatomy 1971 vol.109 no.p- 71 74.

[8]. Garis, Cf, Topography and development of the cecum appendix annals of Surgery 1941 vol 113, no.4, p-540-548

[9]. Gilbert, SR, Emmens, Rw and Putnam, Tc. Appendicitis in children.

[10]. Surgery, gynecology and obstetrics 1982, vol 161 p 261-267.

[11]. Katzarski, M., Gopal rao, UK, Brady k blood supply and position of the Vermiform in Zambia's medical journal of Zambia 1979 vol 13 , no 2, p 32-34.

[12]. Khlystova, Zs and Rabotnikkova, El Developmental of the mucosa of the Lymphocytes of the vermiform appendix of the human fetus.Arbhir Anatomii, Gisstologii, i., Embryologii, 1984, vol.86.no.5, p, 63-68.

[13]. Malas, ma. sulako., Gokcimen, a et al Development of the vermiform Appendix during the fetal period Surgery radiologics anatomy. 2004, vol.26, no3 p., 202-207.

[14]. Malas, Ma. Gokcimen, A and sulak, Growing caecum and Vermiform Appendix fp fetal diagnosis and therapy 2001, vol16, no3, p.173-177.

[15]. Williams,Pl.,Bannister,Lh.,Berry,MM,Collins,P.,Dyson,M.Dussek,Je and Ferguson, Mwj.Alimentary system In WilliamsJe. and M.Dussek. Ferguson,Mwj.,Collins.p.,Dyson., M.Dussek.,Je and Ferguson,Mwj Gray's Anatomy.38 ${ }^{\text {th }}$ Ed New York: Churchill Livingstone, 1995.p.1775-6. 